\title{
SEKOLAH ISLAM TERPADU PENEKANAN PADA ARSITEKTUR HIJAU DI KABUPATEN BONE
}

\author{
Ismail B. Arifin ${ }^{1}$, Marwati ${ }^{2}$, Burhanuddin ${ }^{3}$ \\ Jurusan Arsitektur Fakultas Sains \& Teknologi UIN-Alauddin Makassar \\ E-mail ; Marambodalle@yahoo.com, amin.burhanuddin@gmail.com
}

\begin{abstract}
The development of science and technology that is integrated with the Islamic knowledge wishes to create a potential religious generation. Islamic education institution creates a religious Islamic individual through two approaches; those are natural and cultural approaches. Method that is applied is descriptive, that is collecting and analyzing the primary and secondary data. Then, planning and designing approaches are done to review various aspects oriented with architect knowledge, basic theoretic and standard. The pressure of green architecture concept enclose energy efficiency because in architect concept that is friendly environment, continuing, holistic and based on the efforts to reach designing to create energy efficiency.
\end{abstract}

Keywords : School, Islamic, integrated, architecture, green.

\footnotetext{
${ }^{1}$ Alumni Jurusan Teknik Arsitektur UIN Alauddin Makassar Angkatan 2007

${ }^{2}$ Dosen Jurusan Teknik Arsitektur UIN Alauddin Makassar

${ }^{3}$ Dosen Jurusan Teknik Arsitektur UIN Alauddin Makassar
} 


\section{Pendahuluan}

\section{A. Latar Belakang}

Dalam perkembangan ilmu pengetahuan Islam muncul beberapa konsep lembaga pendidikan Islam seperti Pondok Pesantren namun hanya memproritaskan dengan ilmu agama saja tanpa memikirkan pengetahuan umum. Mengintegrasikan ilmu pengetahuan Islam yang dipadukan dengan ilmu pengetahuan umum, yang disajikan dengan baik dan selalu mengikuti perkembangan zaman dengan mengharapkan lahir generasi Islam yang handal dalam ilmu pengetahuan umum, yang memiliki pondasi awal dari keperibadian dan sikap yang sesuai dengan ajaran agama Islam. Satu konsep yang berkembang dan modern dengan sebutan Sekolah Islam Terpadu.

Peradaban masyarakat modern religius yang diharapkan Sekolah Islam Terpadu sebagai lembaga pendidikan Islam tentunya bukan sekedar produk evolusi natural budaya masyarakat tanpa norma, tetapi merupakan produk budaya yang conditioning yang disosialisasikan dengan kondisi yang diwarnai oleh nilai-nilai budaya yang terdesain serta menggambarkan aktualisasi dari nilai-nilai religius (Al-Qur' an dan Al-Hadits).

Menurut buku Kabupaten Bone Dalam Angka 2012, data pendidikan khusunya jumlah siswa Sekolah Islam (Madrasah sanawiyah/pesantren) yang diterima pada tahun 2011 sebanyak 8.968 orang dan jumlah sekolah 84 buah dengan rasio murid - sekolah 107, sedangkan Sekolah Islam (Madrasah Aliyah/pesantren) yang diterima pada tahun 2011 sebanyak 4.963 orang dan jumlah sekolah 33 buah dengan rasio murid - sekolah 151.

Mengacu pada data sebelumnya bahwa pertumbuhan minat siswa untuk masuk Sekolah Islam sangat signifikan namun dibandingkan rasio jumlah murid dengan bangunan sekolah tidak sebanding. Dari data yang penulis dapatkan bahwa perlunya sebuah wadah pendidikan yang bisa menampung dan meningkatkan daya minat murid untuk sekolah pada Sekolah Islam Terpadu dengan mempertimbangkan berbagai aspek. Antara lain yaitu dengan menerapkan elemen-elemen green building pada perancangan lingkungan sekolah agar murid, guru, pengelola dan pengguna Sekolah Islam Terpadu merasa nyaman berada dalam sekolah serta menjadikan tolak ukur pendidikan di kabupaten Bone.

Dalam proses sebuah sekolah membutuhkan sistem pendidikan yang teratur baik dari segi kurikulum, pengelolaannya, manusia dan bangunannya. untuk memenuhi kebutukan proses belajar yang baik diperlukan faktor kenyamanan yang mendukung agar porses dapat berjalan baik. Sehubungan dengan tema judul penulis yang diambil arsitektur hijau (green building).

\section{TUJUAN, SASARAN \& LINGKUP PEMBAHASAN}

Tujuan Pembahasan Merencanakan bangunan sekolah Islam Terpadu yang hijau di kab. Bone dan merumuskan perencanaan dan perancangan yang berhubungan dengan aspek-aspek perencanaan dan perancangan suatu wadah pendidikan.

Sasaran Pembahasan yaitu menyusun langkah-langkah proses konsep-konsep perencanaan dan perancangan arsitektur terhadap sekolah Islam Terpadu di kab. Bone yang hijau, sebagai acuan terhadap produk perencanaan dan perancangan.

Lingkup Pembahasan dibatasi pada permasalahan yang berkaitan dengan disiplin arsitektur perencanaan dan perancangan sekolah Islam Terpadu penerapan Arsitektur hijau di kab. Bone. 


\section{METODE PEMBAHASAN}

Pembahasan dilakukan dengan metode deskriptif, yaitu dengan mengumpulkan dan menguraikan data primer dan sekunder. Kemudian diolah dan dikaji dengan mengacu pada potensi dan masalah yang muncul, kemudian dilakukan pendekatan perencanaan dan perancangan atas dasar pertimbangan berbagai aspek yang berorientasi pada disiplin ilmu arsitektur, landasan teoritis dan standar yang ada.

\section{KERANGKA FIKIR}

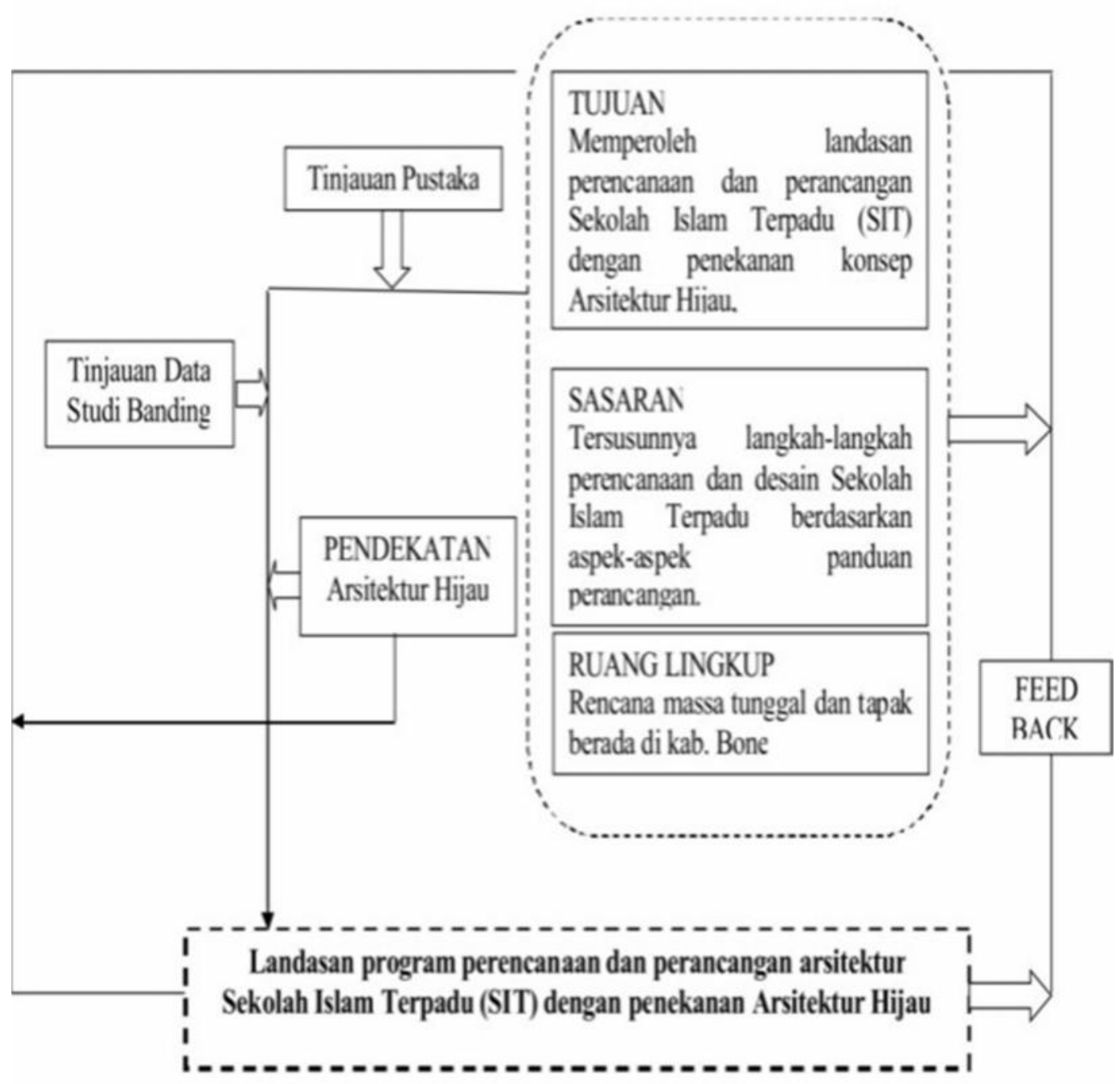

Gambar I.1. Skema Metode Pembahasan (Sumber : Analisis Penulis) 
Nature

\section{KONSEP \& STRATEGI}

\section{PENDEKATAN ARSITEKTUR HIJAU}

Perancangan sekolah islam terpadu ini berada di kawasan iklim tropis lembab dengan curah hujan dan intensitas radiasi matahari yang tinggi sepanjang tahun. Dengan melihat potensi kedua jenis sistem atap dan kesesuaiannya dengan kondisi iklim tropis maka dalam perancangan ini digunakan sistem atap bahan metal deck / bondek yang dikombinasikan dengan beton bertulang, cara ini digunakan karena akan diterapkan penghijauan atap/ green roof.

Dengan penggunaan paving blok / grass blok sebagai perkerasan jalan atau parkir maka air hujan masih dapat meresap ke tanah.

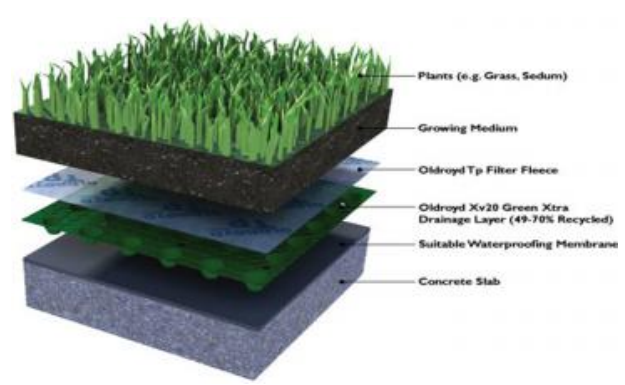

Gambar IV.17. Green roof (http://samudro.wordpress.com, 2013)

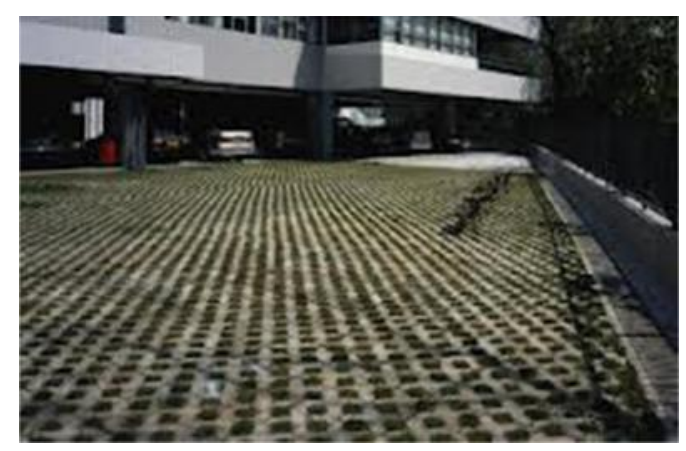

Gambar IV.18 Paving Block

(http://paving-genteng.blogspot.com/, 2013)

\section{PENERAPAN KISI-KISI KAYU DENGAN TANAMAN}

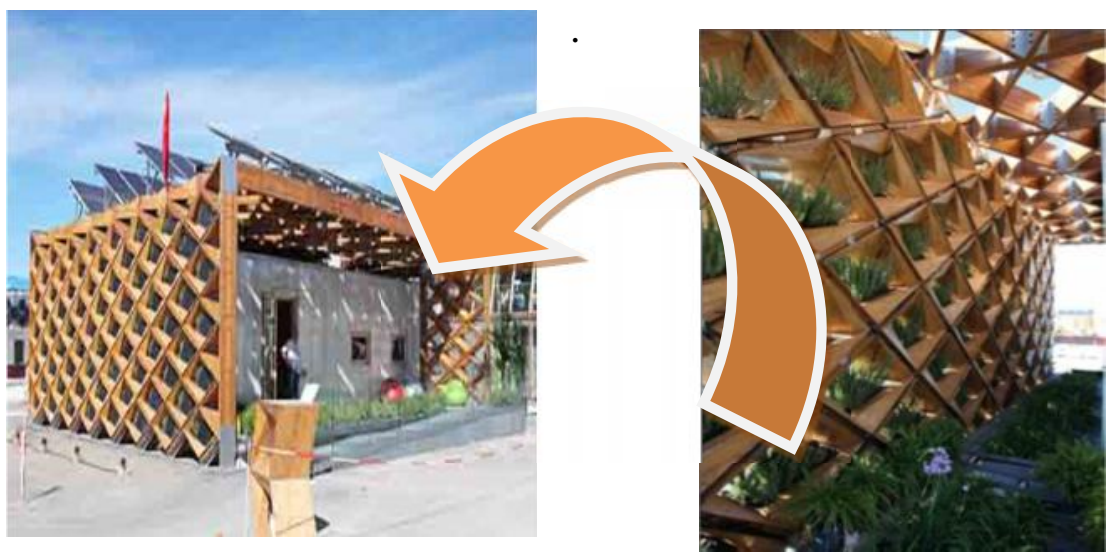

Gambar IV.28. Penerapan kisi-kisi kayu dengan tanaman

( Data pribadi penulis, 2013)

Dari segi pendekatan penghawaan, untuk memkasimalkan penghawaan dengan cara penerapan sistem ventilasi alami pada rancangan dilakukan dengan cara ;

1) Memaksimalkan bukaan alami dengan menerapkan sistem ventilasi silang berupa bukaan pada dinding dengan menanam beberapa tumbuh-tumbuhan pada dinding/shading. 
Nature

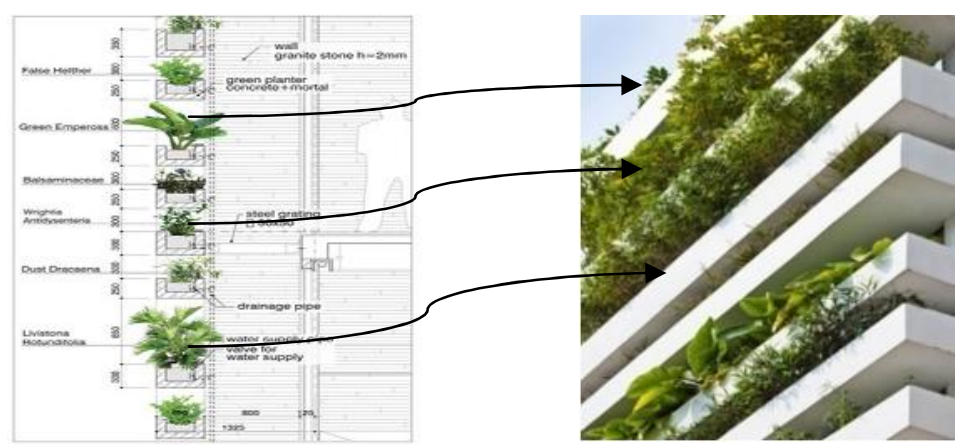

2) Mengatur/mengarahkan pergerakan udara yang masuk melalui arah utara dan selatan,

3) Ruang-ruang yang berpotensi memiliki kelembaban tinggi direncanakan perletakannya agar dapat terjangkau oleh cahaya alami dan udara alami. seperti lavatory direncanakan di sisi timur dan kafetaria di area barat,

4) Mengatur pergerakan udara di dalam tapak. Dengan menata pepohonan agar udara mengalir dengan baik ke dalam bangunan.

5) Meningkatkan kualitas ekologis tapak dengan merencanakan ruang terbuka hijau khususnya pada empat kawasan tapak.

\section{PENERAPAN KONSEP ARSITEKTUR HIJAU.}

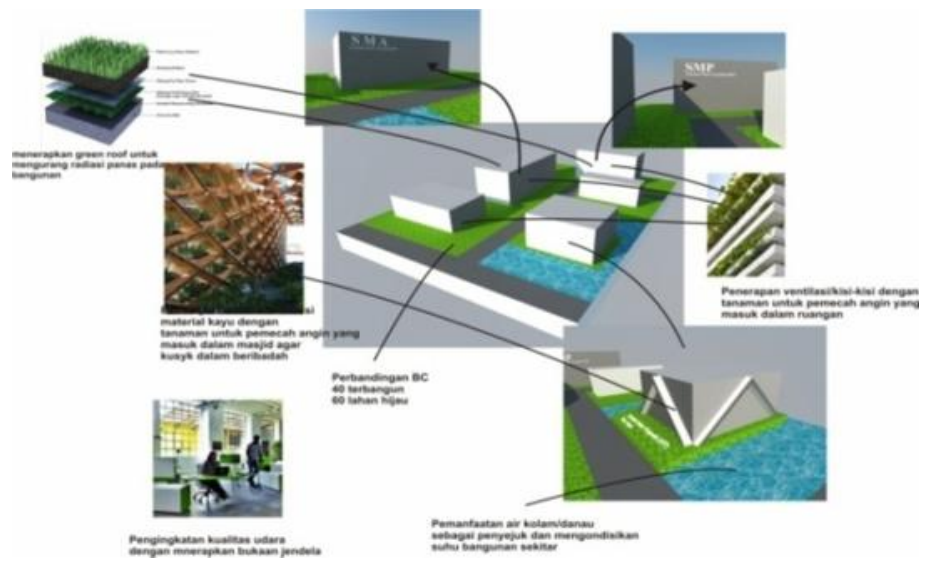

Gambar IV.33 Pendekatan konsep hijau pada desain (Analisa Penulis, 2013)

\section{HASIL PERANCANGAN}

Konsep Perancangan Tapak

Perancangan tapak merupakan hasil analisis dan aplikasi dari pendekatan desain. Perancangan tapak pada Sekolah Islam Terpadu Penekanan Pada Arsitektur Hijau Di Kabupaten Bone merupakan keterpaduan dari beberapa faktor yang menjadi pertimbangan yaitu: tata lingkungan, Alternatif pengolahan tapak, sirkulasi, material, dan penzoningan. 


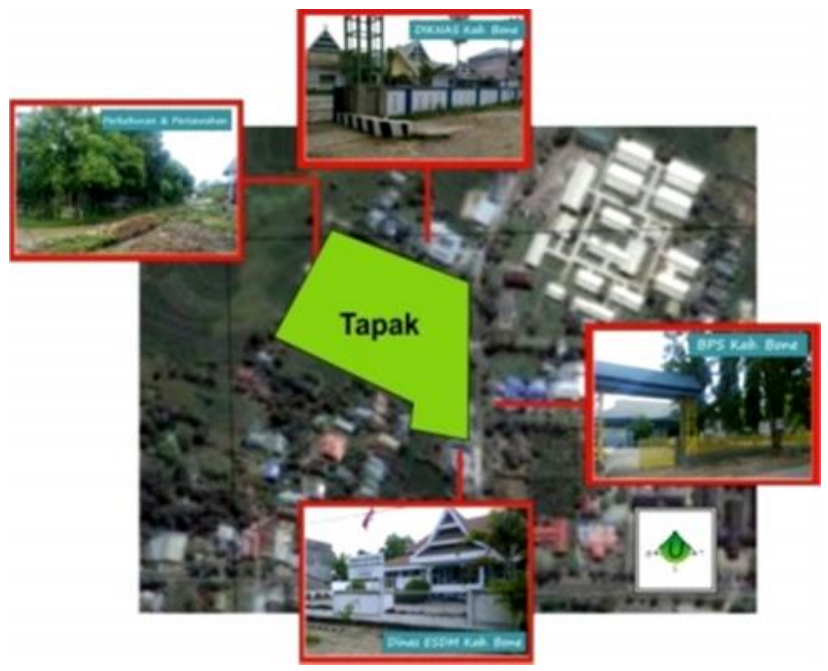

Gambar I.2. Alternatif Pengolahan Tapak, (a) Alternatif 1, (b)Alternatif 2
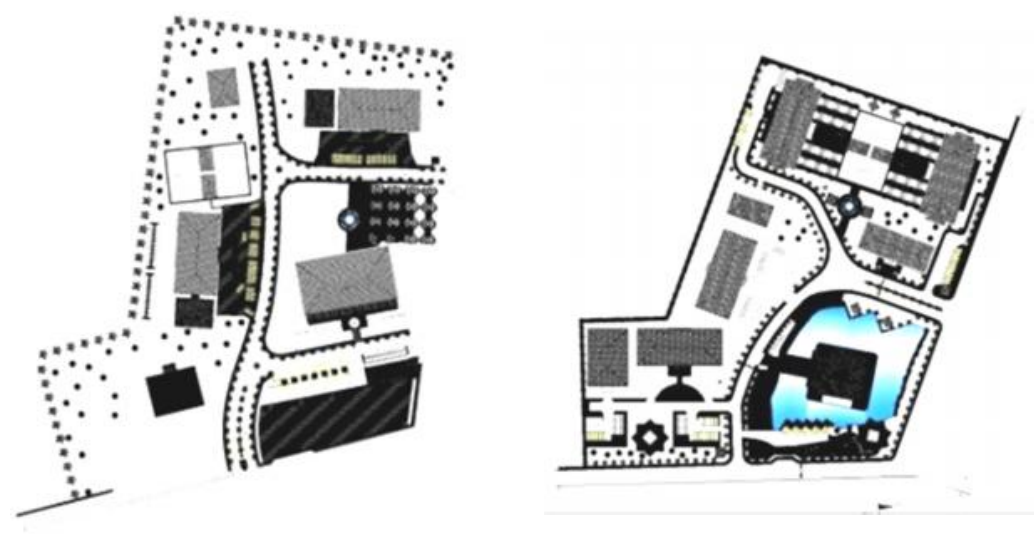

Gambar I.2. Alternatif Pengolahan Tapak, (a) Alternatif 1, (b)Alternatif 2

\section{KONSEP SRUKTUR \& MATERIAL}
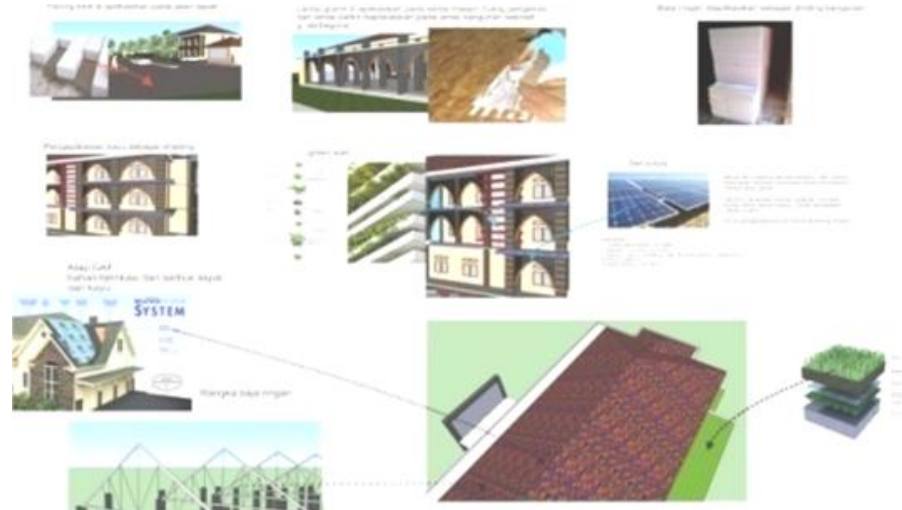

Lit IIIH 
Nature

National Academic Journal of Architecture

\section{KONSEP PENZONINGAN}

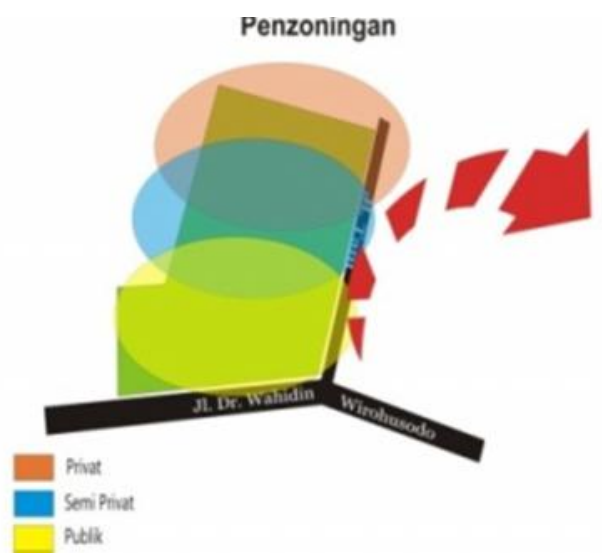

Tanggapan desain

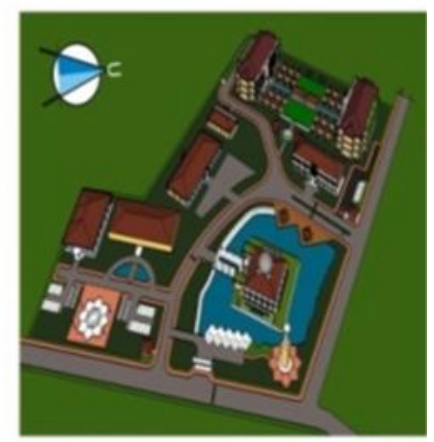

\section{TRANSFORMASI DESAIN}
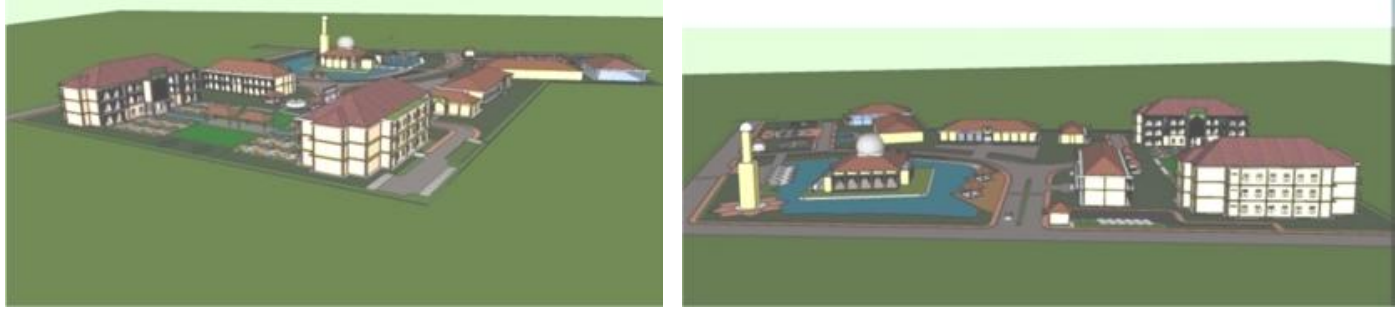

Gambar II.1. Tampak Barat Desain (Sumber: Data Pribadi)

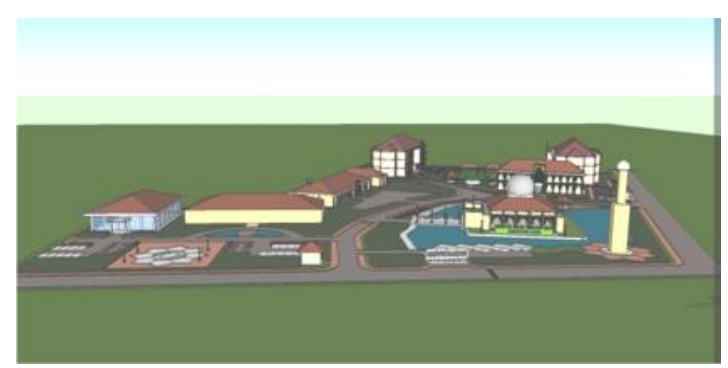

Gambar II.2. Tampak Utara Desain (Sumber: Data Pribadi)
Gambar II.2. Tampak Utara Desain (Sumber: Data Pribadi) 


\section{PRODUK DESAIN}

\section{Site Plan}

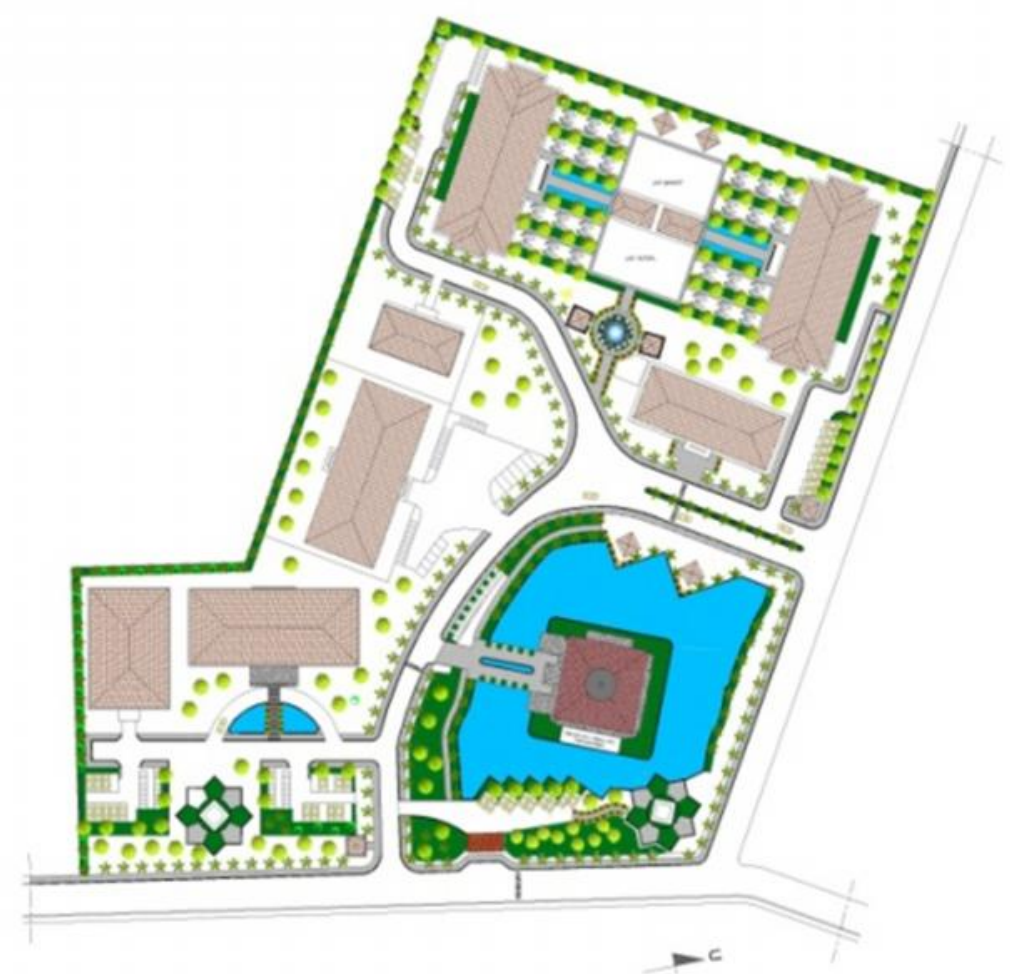

Gambar III.1. Site plan SIT

(Sumber: Data Pribadi)

\section{BANGUNAN UTAMA Gedung SMP dan SMA}

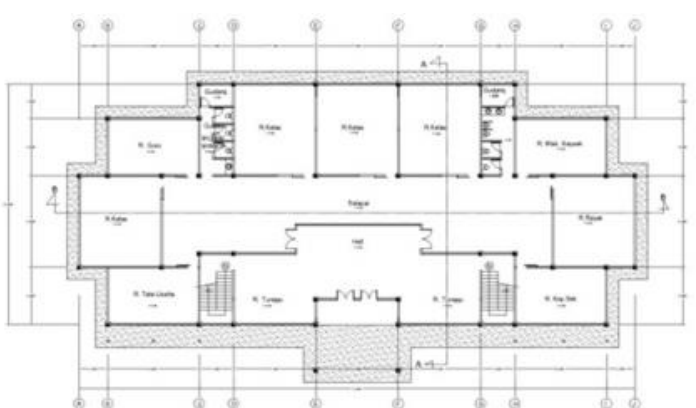

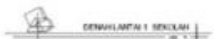

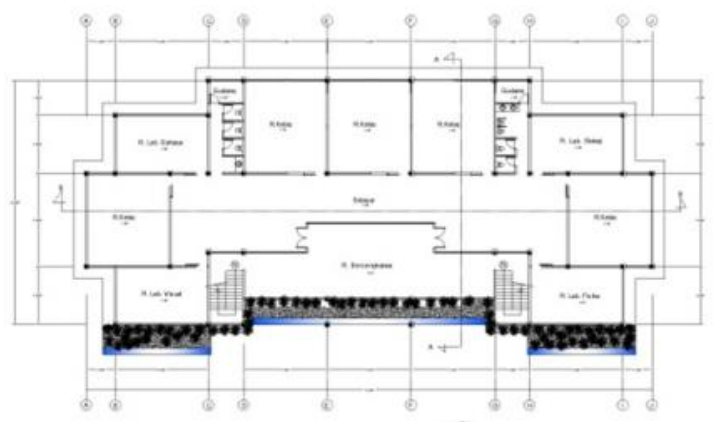

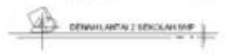

Denah Lantai 2 SMP \& SMA (Sumber: Data Pribadi)
Denah Lantai 1 SMP \& SMA (Sumber: Data Pribadi) 
Nature

National Academic Journal of Architecture

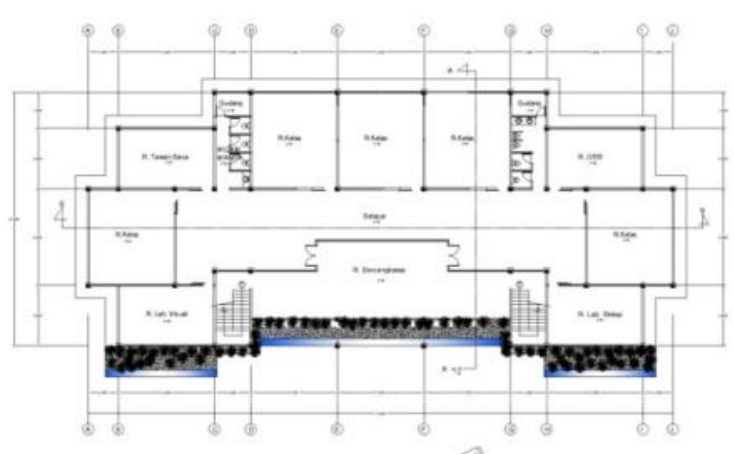

Q

Denah Lantai 3 SMP \& SMA

(Sumber: Data Pribadi

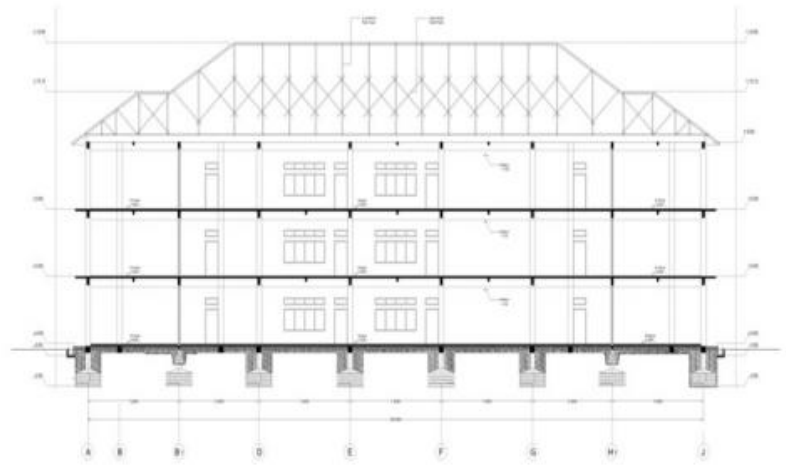

Potongan Bangunan Sekolah (Sumber: Data Pribadi)

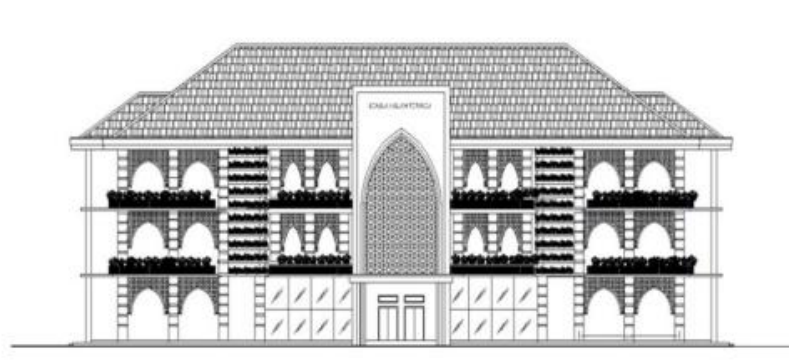

Tampak Depan Sekolah (Sumber: Data Pribadi)

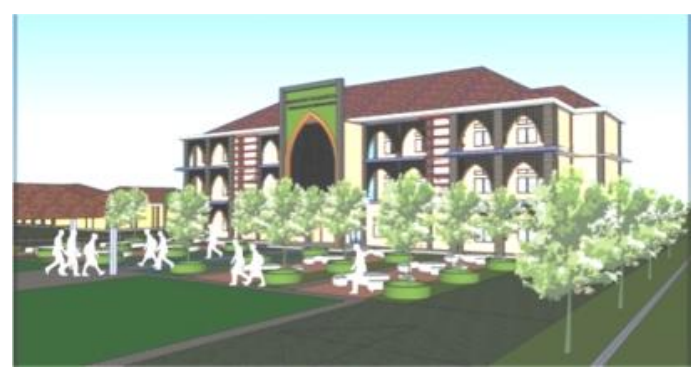

Perspektif Sekolah

(Sumber: Data Pribadi) 
Nature

National Academic Journal of Architecture 
Nature

National Academic Journal of Architecture 
Nature

National Academic Journal of Architecture

\section{PERSPEKTIF KAWASAN}

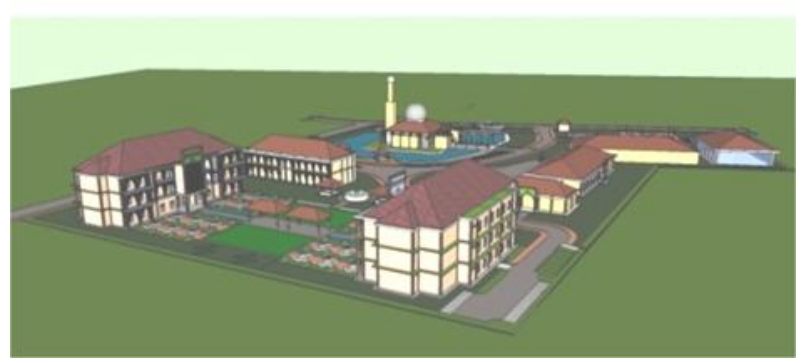

Tampak Barat Desain (Sumber: Data Pribadi)

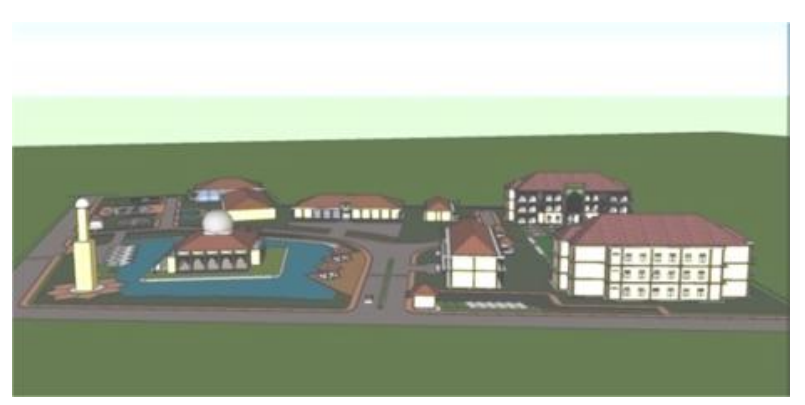

Tampak Utara Desain (Sumber: Data Pribadi)

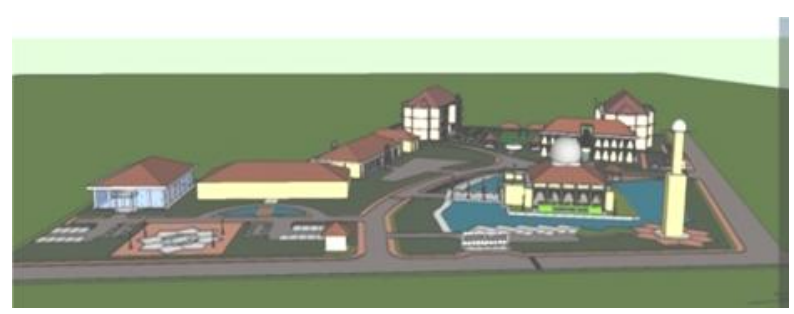

Tampak Timur Desain (Sumber: Data Pribadi)

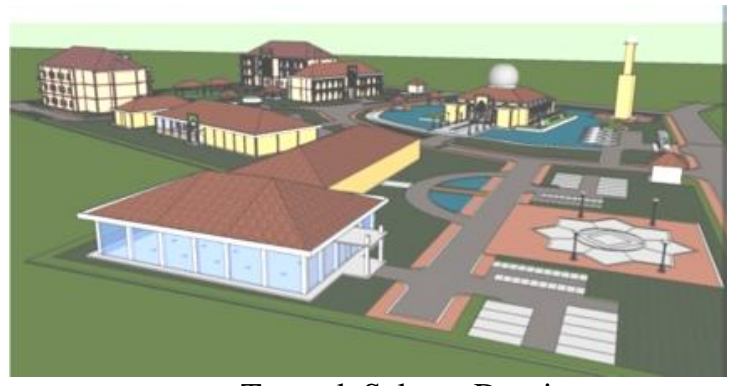

Tampak Selatan Desain

(Sumber: Data Pribadi)

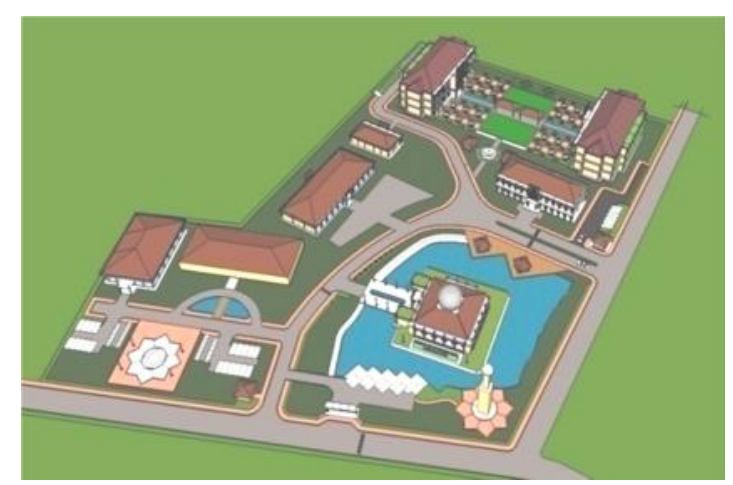

Desain Akhir (Sumber: Data Pribadi)

\section{DAFTAR PUSTAKA}

Agoes Soeganto, 2005. Ilmu Lingkungan. Surabaya: Air langga University Press

Departemen Agama RI, Sejarah Madrasah; pertumbuhan, dinamika dan perkembangan di Indonesia, Jakarta : tahun 2004

Karyono, Tri Harso.2010.Green Architecture 'Pengantar Pemahaman Arsitektur Hijau di Indonesia. Rajawali Pers:Jakarta

Nata, Abuddin. (editor)(2001). Sejarah Pertumbuhan dan Perkembangan Lembaga-Lembaga Pendidikan Islam di Indonesia, Jakarta: Grasindo

Pickard, Quentin. 2002. The Architect's Handbook. 
Nature

National Academic Journal of Architecture

Blackwell Science Ltd, USA.

Satwiko, Prasasto. 2005. Arsitektur Sadar Energi. Penerbit Andi, Yogyakarta.

Satwiko, Prasasto. 2009. Fisika Bangunan. Penerbit Andi, Yogyakarta 